\title{
A NEUROPSYCHIATRIC INAUGURAL PRESENTATION OF AN HIV INFECTION - A CASE STUDY
}

\author{
N. Descalço, C. Santos, G. Borges, F. Vicente
}

Department of Psychiatry and Mental Health, Hospital Garcia de Orta, Almada, Portugal

\section{Introduction}

Human immunodeficiency virus (HIV) infection can cause neuropsychiatric disorders such as cognitive impairment, behavioral difficulties or psychiatric symptoms - for instance, mania and psychosis - that are related to a wide variety of factors, including the direct effects of the virus, other cerebral infections caused by immune susceptibility (opportunistic infections), the preexisting psychiatric conditions and personality vulnerabilities. Most of the neuropsychiatric symptoms are associated with late stage HIV infection.

Opportunistic infections (such as cerebral toxoplasmosis, cryptococcosis and $P$. jirovecii pneumonia), are usually AIDS-defining conditions. An estimated $30 \%$ to $50 \%$ of HIVpositive individuals infected with $T$. gondii develop cerebral toxoplasmosis, which is associated with high mortality.

\section{Case report}

An 32 years-old man presents to the Psychiatric ER as a "not identified male". He was found wandering alone, disoriented, suspicious, with soliloquies but unintelligible speech.

Further evaluation in the ER included CT scan, which showed multiple ring-enhancing brain lesions associated with edema. The drug tests were positive for cannabinoids.

HIV serology was positive and the patient was admitted to the Infectious Diseases Ward with the diagnosis of cerebral toxoplasmosis.
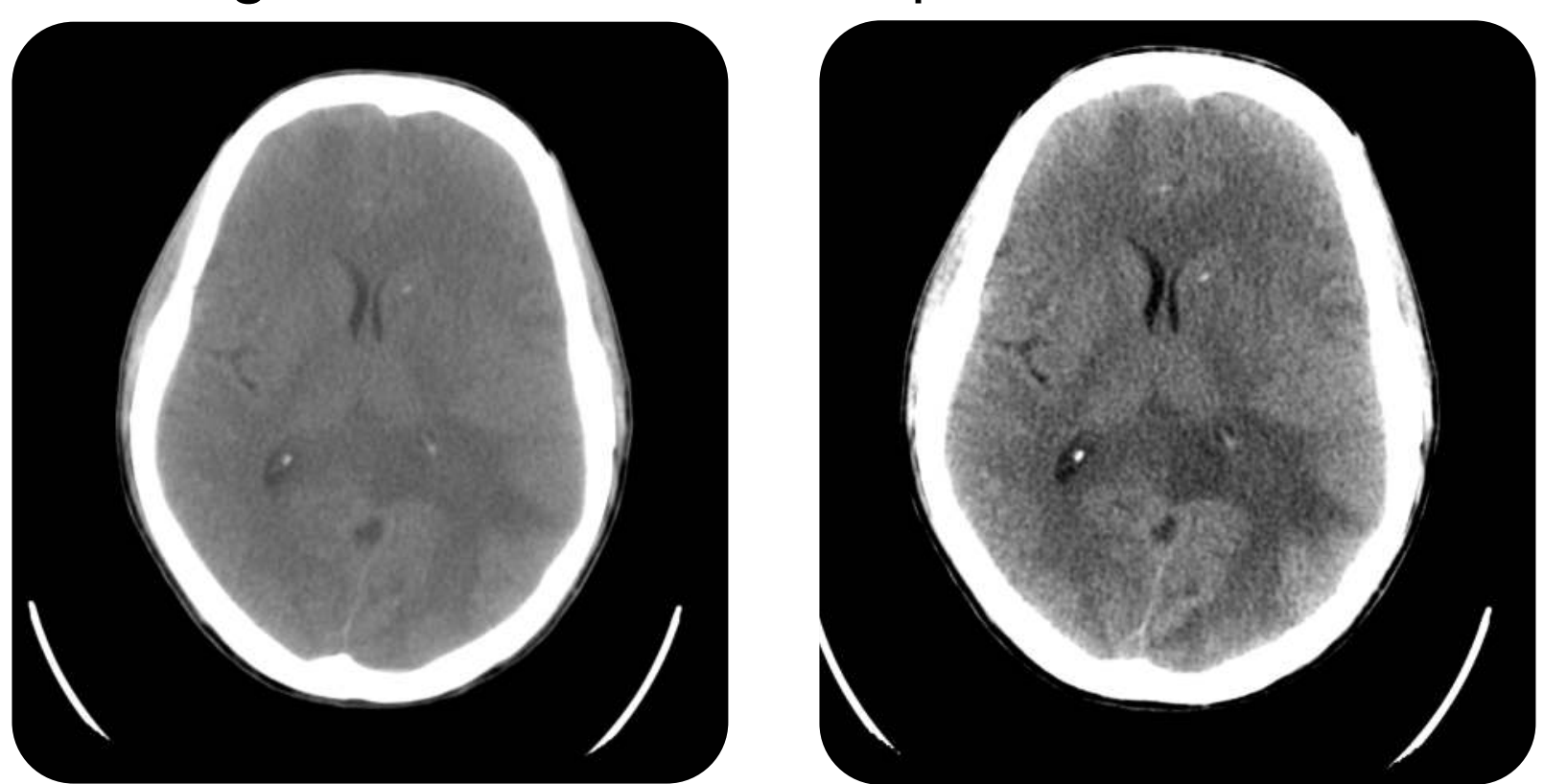

Interviewing his ex-wife (the only family member available) it was possible to establish a change of behavior in the 3 months prior to hospital admission: he had break up with his wife, been living in a homeless situation and stopped recognizing his family and friends. He also stopped taking care of his hygiene. He had no medical history and the HIV infection was not known. Laboratorial evaluation showed up:

- CD4+ cell count $72 \mathrm{cel} / \mathrm{mL}$ (6.4\%)

- HIV-1 viral load $1318257 \mathrm{copies} / \mathrm{mL}$

- CD4/CD8 ratio 0.08

- Positive for cryptoccocical infection and toxoplasmosis

He was submitted to the adequate treatment but about two months after admission he passed away, as it was not effective.
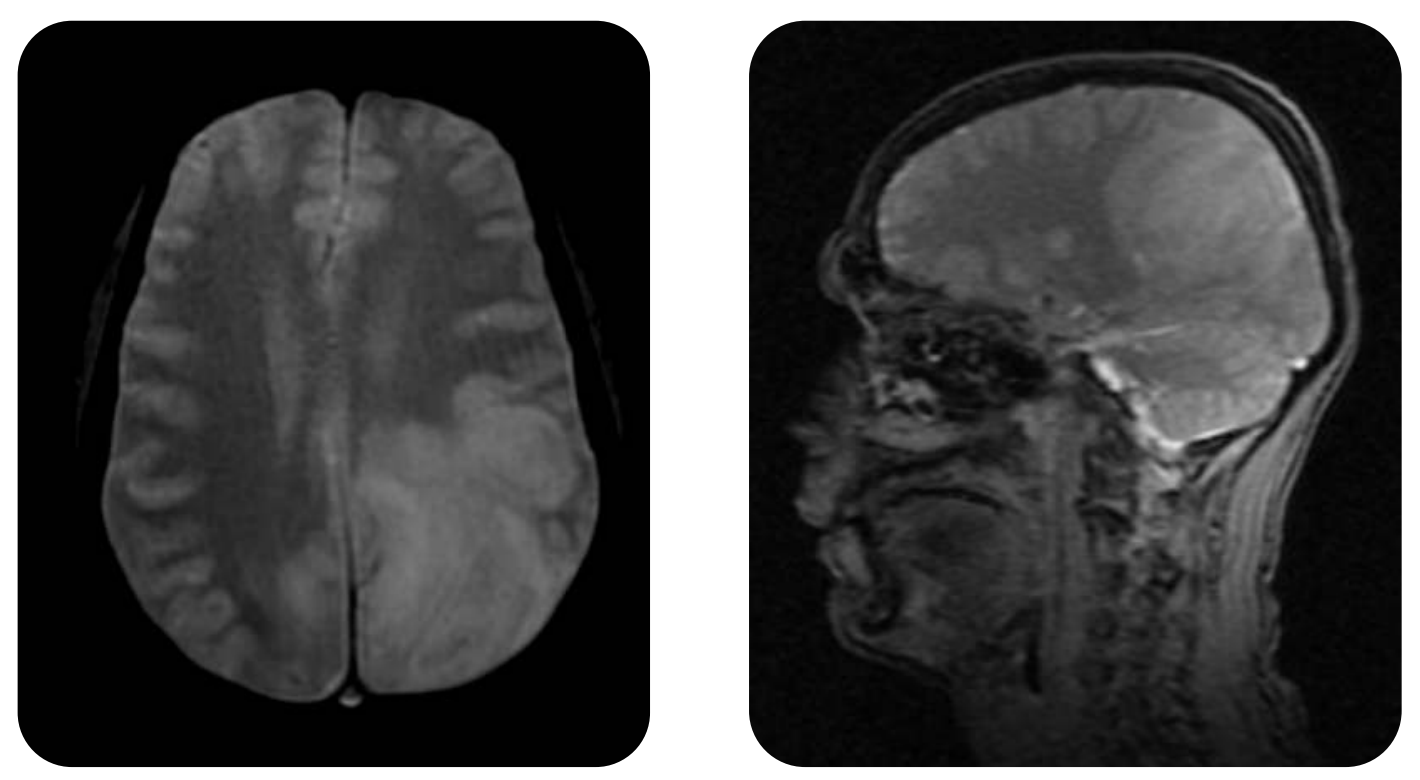

Images 3 and 4 - MRI

\section{Conclusion}

In this case, the neuropsychiatric symptoms were the manifestation of an opportunistic infection related to HIV progression. Although it may be common in this cases, it is not frequent to find them in inaugural presentations. This patient had any prior medical or psychiatric comorbidity and it was mandatory to exclude organic diseases before considering a primary psychiatric disease. Considering the pleiomorphic presentation of multiple organic diseases, such causes should always be excluded in patients presenting to the ER with psychiatric symptoms.

\section{References:}

De Oliveira, G. B., da Silva, M. A. L., Wanderley, L. B., et al 2016). Cerebral toxoplasmosis in patients with acquired immune deficiency syndrome in the neurological emergency department of a tertiary Knital. Clinical Neurology and Neurosurgery, 150, 23-26.

Knights, M., Chatziagorakis, A., \& Kumar Buggineni, S. (2017). HIV infection and its psychiatric manifestations: A clinical overview. BJPsych Advances, 23(4), 265-277.
$\Gamma_{1}$ 